\title{
Tagged Halloysite Nanotubes as a Carrier for Intercellular Delivery in Brain Microvascular Endothelium
}

\author{
Mahdi Yar Saleht, Neela Prajapatit, Mark A. DeCoster* and Yuri Lvov* \\ Institute for Micromanufacturing and Biomedical Engineering Program, Louisiana Tech University, Ruston, LA, United States
}

OPEN ACCESS

Edited by:

Stefano Leporatti,

Institute of Nanotechnology, Italian

National Research Council, Italy

Reviewed by:

Marina Massaro,

University of Palermo, Italy

Mel De Villiers,

University of Wisconsin-Madison,

United States

Xiangyang Shi,

Donghua University, China

*Correspondence:

Mark A. DeCoster

decoster@latech.edu

Yuri Lvov

ylvov@latech.edu

${ }^{\dagger}$ These authors have contributed equally to this work

Specialty section:

This article was submitted to

Nanobiotechnology,

a section of the journal

Frontiers in Bioengineering and

Biotechnology

Received: 13 March 2020

Accepted: 20 April 2020

Published: 14 May 2020

Citation:

Saleh MY, Prajapati N,

DeCoster MA and Lvov Y (2020) Tagged Halloysite Nanotubes as a Carrier for Intercellular Delivery

in Brain Microvascular Endothelium.

Front. Bioeng. Biotechnol. 8:451.

doi: 10.3389/fbioe.2020.00451
Neurological disorders that are characterized by unpredictable seizures affect people of all ages. We proposed the use of nanocarriers such as halloysite nanotubes to penetrate the blood-brain barrier and effectively deliver the payload over an extended time period. These 50-nm diameter tubes are a natural biocompatible nanomaterial available in large quantities. We proved a prolonged gradual drug delivery mechanism by the nanotube encapsulating rhodamine isothiocyanate and then ionomycin into brain microvascular endothelial cells (BMVECs). Through delayed diffusion, the nanotubes effectively delivered the drug to the primary BMVECs without killing them, by binding and penetration in time periods of 1 to $24 \mathrm{~h}$.

Keywords: halloysite (HNT), brain delivery, endothelia cell, nanomaterial application, drug-drug interactions

\section{INTRODUCTION}

Brain diseases, such as central nervous system disorders, are of the most poorly treated diseases in today's world. Occurring frequently in people of all ages, impacting their way of life, and increasing the chances of premature death. Epilepsy is a common example of a neurological disorder that is characterized by unpredictable seizures that results in unusual behavior, such as involuntary movements. Around the globe today, an estimated 50 million people are diagnosed with this disorder causing it to be one of the most common brain diseases. Thus, if the disease could be treated properly through various methods, such as nanotechnology, up to $70 \%$ of diagnosed patients could be cured (Silva, 2008; Bennewitz and Saltzman, 2009; Pehlivan, 2013; World Health Organization [WHO], 2020). Current anti-seizure medication has a wide range of side effects which include dizziness, tiredness, and trouble speaking. Utilizing nanosized carriers is an effective route to determine targeted and slow release drug delivery techniques to minimize these side effects and provide an overall more effective treatment. Using less than $50 \mathrm{~nm}$ capsules promises better penetration into cells, especially if one uses tubule drug carriers which have improved efficiency in passing cell membrane as defined by the smallest cross-section size. Gamma-amino- $n$-butyric acid (GABA), glutamic acid, and dopamine are important brain neurotransmitters for epilepsy research, and their nano-formulation for intracellular sustained delivery is promising for higher efficiency.

Brain microvascular endothelial cells (BMVECs) are the key cells in the blood-brain barrier, which is the multicellular membrane between the brain's blood vessels and a brain tissue. BMVECs constitutes the tight junction proteins which prevent the entry of pathogens and other toxic substances into the brain, but it also prevents most potential drugs against neurological and mental disorders to cross the barrier and readily reach into the brain tissue (Mahringer et al., 2013; Lvov et al., 2016). We exploit halloysite clay nanotubes (HNT) to penetrate the endothelial cells and effectively deliver the payload over an extended time. Our hypothesis is based on the conception of "nano-torpedo" when rod-like tubule hollow clay capsules bind or penetrate through 
cell membrane exploiting its very small, 50-nm diameter crosssection and deliver the drug load in the interior.

Halloysite nanotubes are formed by 10-15 revolutions of $0.7 \mathrm{~nm}$ thick kaolin aluminosilicate sheets and have diameters ranging between 50 and $60 \mathrm{~nm}$, lumen diameters of 12-15 nm, and lengths within 500-900 nm (Figure 1) (Liu et al., 2014; Lvov et al., 2016). It is an environmentally friendly, natural, and cheap tubule nanomaterial available in large quantities. Halloysites outer surface is composed of $\mathrm{SiO}_{2}$, and the tube's interior is composed of $\mathrm{Al}_{2} \mathrm{O}_{3}$, which are oppositely (negative/positive) charged in the $\mathrm{pH}$ range of 3-9. The structure of halloysite in Figure 1 shows how the payload can be loaded inside the positively charged lumen of halloysite, which is especially efficient for spontaneous adsorption of negatively charged drug molecules. Based on geometrical sizes of halloysite, one may conclude the maximal volume load inside the tubes of 10-12 vol.\%, which may reach for organic drugs ca 15 wt.\%. This is a typical drug load given in many publications, as summarized in Santos et al. (2019). Higher drug loading means that drug molecules are adsorbed on the tube external surface, which may change the formulation properties that are observed through zeta-potential and colloidal stability. Zeta potential is an important though indirect indication of the innermost drug loading. Thus, inner adsorption of negative molecules usually increases the electrical potential magnitude from ca. $-30 \mathrm{mV}$ in pristine to minus $45-50 \mathrm{mV}$ in loaded nanotubes, simultaneously improving the sample colloidal stability (Liu et al., 2019). Drugs that were used are khellin, oxytetracycline, gentamicin, ciprofloxacin, vancomycin, atorvastatin, metronidazole, dexamethasone, doxorubicin, furosemide, nifedipine, curcumin, resveratrol, povidone iodine, amoxicillin, brilliant green, chlorhexidine, and DNA and viral genes were also successfully loaded in halloysite (Santos et al., 2019).

Halloysite is a biocompatible material with low toxicity assessments (Vergaro et al., 2010; Dzamukova et al., 2015b; Kruchkova et al., 2016; Hu et al., 2017; Kamalieva et al., 2018; Mehdia et al., 2018; Wang et al., 2018; Fakhrullina et al., 2019; Zhao et al., 2019). Many researchers reached a consensus that these clay nanotubes are safe up to a $10 \mathrm{mg} / \mathrm{mL}$ formation, which is less toxic than common table salt (Vergaro et al., 2010). This was tested on several in vitro and in vivo systems: cells lines, microworms, infusoria, fishes, mice, and rats (Santos et al., 2019). The only minor toxic effect was found with high oral halloysite consumption. When acidic clay decomposes, the

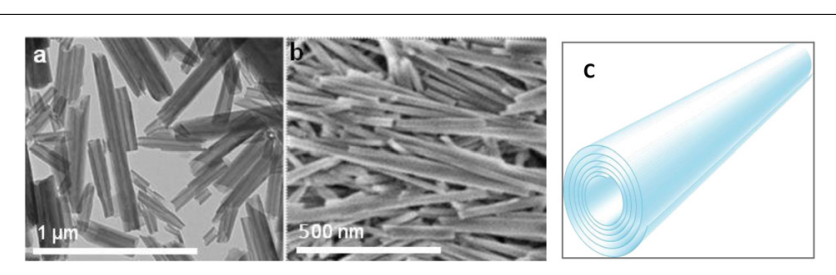

FIGURE 1 | A TEM and SEM image of halloysite nanotubes (a,b). A scheme of rolled clay (c). stomach increased $\mathrm{Al}^{3+}$ accumulation (Kamalieva et al., 2018). The mice that were orally fed with low nanoclay doses $(5 \mathrm{mg} / \mathrm{kg}$ mice weight, which corresponds to $3 \mathrm{~g}$ of halloysite daily consumption for adult human for 1 month) have shown no oxidative stress or other toxicity signs, and even demonstrated higher growth rates.

Clay nanotube loaded with drugs will penetrate cells more efficiently than spherical particles of the same mass (Dzamukova et al., 2015a; Wang et al., 2018). This approach allowed for an effective halloysite delivery of doxorubicin and other anticancer drugs (Yang et al., 2016; Zhang et al., 2019). HNT/brilliant green formulations with intracellular delivery allowed for preferable elimination of human lung carcinoma cells (À549) as compared with hepatoma cells (Hep3b) due to different -intracellular penetration (Dzamukova et al., 2015a).

In this work, we studied halloysite nanotube penetration into primary rat BMVECs, which are the main cell type that prevent entry of drugs through the blood-brain barrier. We demonstrated with fluorescent rhodamine B isothiocyanate dye that halloysite binds on the cell, penetrates the cell interior, concentrates around the nuclei, and may deliver a drug load. Next, we developed a model for brain cell stimulation using halloysite loaded with ionomycin, a widely used $\mathrm{Ca}^{2+}$ ionophore (Morgan and Jacob, 1994; Kaushik et al., 2018; Long et al., 2018; Wu et al., 2018) to monitor calcium transport across membrane and to stimulate a response from brain cells. IonomycinHNT formulations resulted in intracellular delivery, which was monitored by $\mathrm{Ca}^{2+}$ changes in the cells, showing gradual and prolonged delivery of ionomycin into the brain endothelial cells. An outline in Scheme $\mathbf{1}$ displays the progressive change in calcium signals throughout the stimulation, proving halloysite formulations have the potential as an efficient carrier for drugs or selected neurotransmitters (glutamate) targeted for brain disorders treatments.

\section{MATERIALS AND METHODS}

\section{Halloysite Loading With Rhodamine Isothiocyanate}

Halloysite samples were prepared by loading rhodamine B isothiocyanate (RITC) and ionomycin through stirring, centrifugation, and sonication at various ratios including $10 \mathrm{mg}$ halloysite/1 $\mathrm{mL}$ DI water per $0.5,1$, and $2 \mathrm{mg}$ of RITC. The solutions were then sonicated and vortexed for $1 \mathrm{~min}$, then mixed on a stir plate for $24 \mathrm{~h}$ at room temperature. The mixture was washed once by centrifugation at $2500 \mathrm{RPM}$ for $2.5 \mathrm{~min}$ and then dried at $70^{\circ} \mathrm{C}$ for $24 \mathrm{~h}$. When loading ionomycin, $20 \mathrm{mg}$ of pristine halloysite clay nanotubes were stirred with $1 \mathrm{mM}$ ionomycin for $24 \mathrm{~h}$. The mixture was then washed with sterile water by centrifugation 2500 RPM for 3 min one time. The solution was then freeze dried for $20 \mathrm{~min}$ and placed in a vacuum for $24 \mathrm{~h}$ to remove the excess solution. Samples were then characterized by the zeta potential analyzer, which displays the surface charge and thermogravimetric analysis, allowing us to calculate the loading percentage. 


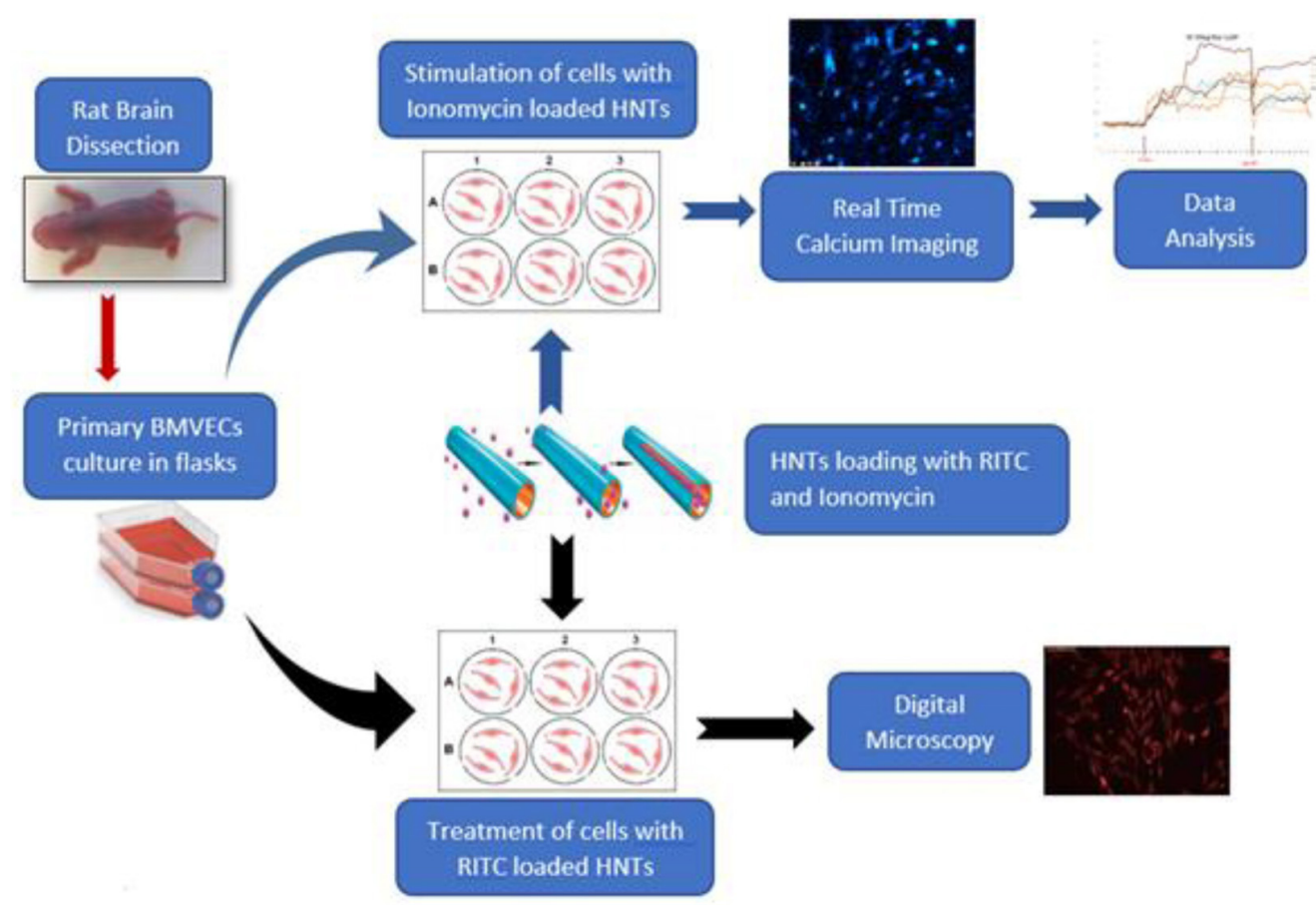

SCHEME 1 | Loading clay nanotubes with fluorescent rhodamine (RITC) and ionomycin and treating the endothelium cells with the loaded nanotubes. lonomycin-HNT upper route with $\mathrm{Ca}^{2+}$ imaging monitoring and RITC - lower route accomplished with visualization.

\section{Neurotransmitter Loading}

This procedure is accomplished by taking $50 \mathrm{mg}$ of etched or pristine halloysite with $50 \mathrm{mg}$ of glutamic acid separately in $5 \mathrm{~mL}$ of DI water, creating a super saturated solution through sonication for $5 \mathrm{~min}$ and stirring for $24 \mathrm{~h}$ at room temperature. The last step is for the suspensions to dry in the oven for $24 \mathrm{~h}$ at $70^{\circ} \mathrm{C}$. After loading the halloysite samples were characterized through zeta potential analyzer and thermogravimetric analysis to determine a surface charge and measure the percentage of material loaded.

\section{Cell Culture}

Primary brain microvascular endothelial cells (BMVECs) were obtained directly from the rat brain cortex. Rat pups, 1 or 2 days old were euthanized to obtain the rat brain cortex. Cortex obtained by dissection of the pup's skull is cleared out of meninges under the microscope. The cortical tissue thus obtained were then treated with trypsin and triturated, with the process repeated at least three times in order to break the brain tissue into cells. After each trituration, cells were incubated at room temperature under sterile conditions for about $10 \mathrm{~min}$ and supernatant was collected in a $15 \mathrm{~mL}$ tube. The collected supernatant was then centrifuged to obtain a pellet of mixed culture of brain cells. BMVECs were isolated from this primary culture by treating them with $5.5 \mu \mathrm{M}$ of puromycin dihydrochloride to kill all other cell types except the endothelial cells as shown in Figure 2A. Endothelial cells are encoded with a puromycin $N$-acetyl transferase gene (PAC gene), which confer resistance to the action of puromycin (Thiel and
Audus, 2001; Wang et al., 2012). Thus, isolated BMVECs were then cultured in vitro at $5 \% \mathrm{CO}_{2}$ and $37^{\circ} \mathrm{C}$ in rat endothelial growth medium (Sigma Aldrich). The cells were characterized by staining them against Von Willebrand Factor (VWF), Figure 2B, an essential blood clotting protein specific to endothelial cells (Mbagwu and Filgueira, 2020).

\section{Treatment With \\ Rhodamine Isothiocyanate (RITC) Loaded Halloysites}

Brain microvascular endothelial cells between primary passages of 3 and 7 were used for the experiments. Cells were plated in 48 well cell culture plates at $10 \mathrm{~K}$ per well density and treated with RITC loaded halloysite, halloysite alone (negative control) and RITC alone (positive control) at 50-70\% confluency. Cells were treated with $10 \mu \mathrm{g} / \mathrm{mL}$ of halloysite alone (negative control) and $10 \mu \mathrm{g} / \mathrm{mL}$ of halloysite loaded with RITC [for all nanoclay samples loaded with different concentration of RITC (1:5 and 1:10)]. The concentration of RITC alone was chosen to correspond to the loaded halloysite formulations.

\section{Brain Microvascular Endothelial Cells (BMVECs) Stimulation Using lonomycin Loaded Halloysite}

Primary BMVECs were plated at the density of $10 \mathrm{~K}$ per well in 48 well plates. At the confluency of 70 to $80 \%$ each well-containing the cells were loaded with $500 \mu \mathrm{L}$ of Fluo-3 AM loading solution, i.e., Lockes' solution with Fluo-3 AM dye (1:500) and pluronic 


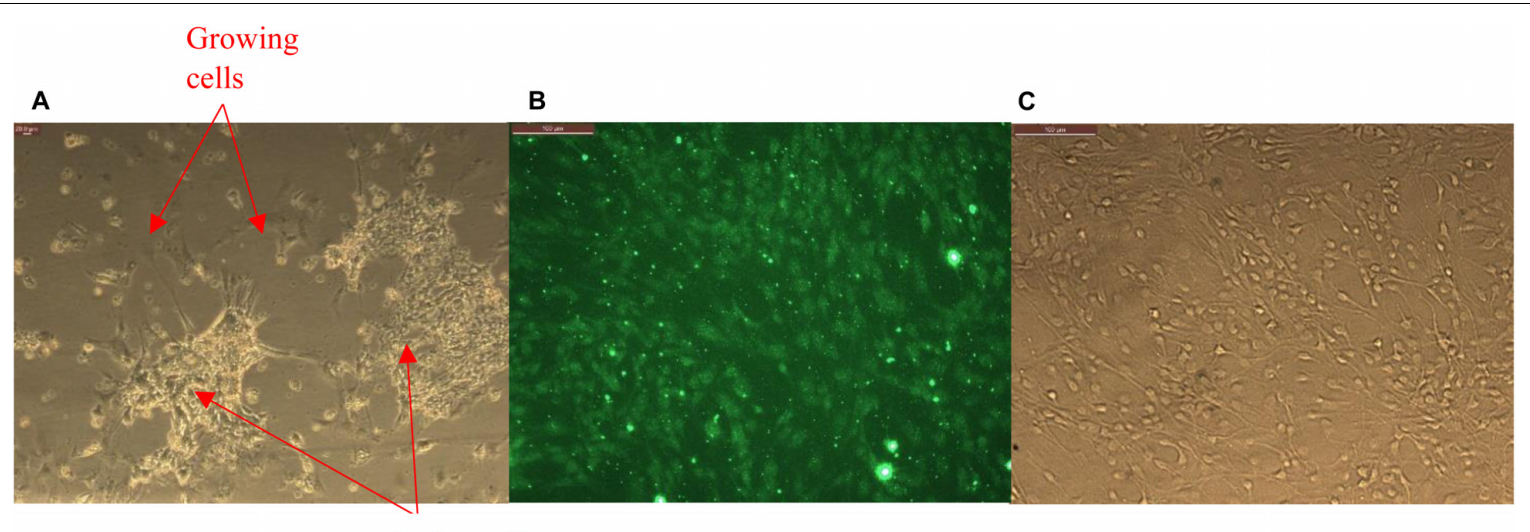

Dying cells

FIGURE 2 | (A) Primary glia treated with puromycin for isolation of brain microvascular endothelial cells (BMVECs) showing killing of all other cell types except the BMVECs. (B) Primary BMVECs characterized by staining against WWF using fluorescence microscopy, and (C) phase image of stained cells.

acid (1:1000) (Yamamoto et al., 2011). The cells were treated with this solution for $1 \mathrm{~h}$ at $37^{\circ} \mathrm{C}$, in $5 \% \mathrm{CO}_{2}$ incubator and then - with $500 \mu \mathrm{L}$ of recovery solution for $1 \mathrm{~h}$. The recovered cells were then stimulated with halloysite loaded with ionomycin (10 and $50 \mu \mathrm{g} / \mathrm{mL}$ ), halloysite alone (50 $\mu \mathrm{g} / \mathrm{mL})$, ATP $100 \mu \mathrm{M}$, and ionomycin $1 \mu \mathrm{M}$ at different instances depending on the experiment. Real time intracellular calcium $\left(\mathrm{Ca}^{2+}\right)$ change due to ionomycin transport across the system was recorded by capturing images every $4 \mathrm{~s}$ with InCyt Im 1 software on the imaging system. The images were then used for $\mathrm{Ca}^{2+}$ signal analysis, which utilizes change in fluorescence intensity as the function of time as a measure for quantifying calcium changes in cells.

\section{RESULTS}

\section{Intracellular Rhodamine Isothiocyanate (RITC) Delivery With Clay Nanotubes}

An observation of halloysite binding and penetration into the endothelial cells was visualized as red fluorescence concentrated within the cells, Figure 3. The addition of only RITC dye did not color the cells interior within $30 \mathrm{~min}$ of treatment; while the dye loaded halloysite bound or penetrated the cells and start releasing the dye inside the cells, coloring them red. Within a 4-h time frame RITC and RITC-HNT both showed cells with more fluorescence compared to the same samples in the $30 \mathrm{~min}$ exposure time. Furthermore, RITC-HNT formulations displayed greater fluorescence compared to RITC only, proving the dye delivery into the cells.

The timeframe of these images is $30 \mathrm{~min}$ after delivery of both samples (RITC and HNT + RITC) to the cells, with a concentration of $10 \mu \mathrm{g} / \mathrm{mL}$ for HNT + RITC and $2 \mu \mathrm{g} / \mathrm{mL}$ of RITC alone. The loading of RITC in HNTs was 20 wt.\%, thus making the same amount of RITC added to the samples. The small bright dots found in the bottom images of Figure $3 \mathrm{E}$ are the aggregated halloysite tubes that contain RITC. HNT-RITC aggregation is displayed mostly along the cellular membrane and inside the endothelial cells as indicated by nuclear exclusion.
Therefore, halloysite nanotubes are highly capable of encapsulating, transporting, and slowly releasing the dye (or drugs as we will show with an example of ionomycin) over a few hours. It is important to note that we did not modify the surface of the halloysite with any type of polymer or silane coating. Figure $\mathbf{3 B}$ displays RITC alone added at the same concentration showing a much dimmer visualization of the cell's responsiveness to this non-encapsulated dye.

Results for the 24-h treatment were similar with more profound fluorescence in both conditions but RITC loaded halloysite delivered more dye into the cells at every time period as compared to just the dye alone, Figure 4. Images at a time point of $24 \mathrm{~h}$ displayed the nanotubes distribution more evenly over the cell interior, still contained within the cell body Figure 4. One could see that RITC-HNT concentrated in some smaller spots of ca $1 \mu \mathrm{m}$ dimeter, which may be the nuclear surrounding, as it was found for MCF-7 cells treated with halloysite (Vergaro et al., 2010). Throughout the trials, we detected a nuclear exclusion, extended length of fluorescence, and that the tubes did not stress or kill the cells. The clay nanotubes are displayed as small dots in Figure 4E and are brighter than the dye spread inside the cells. The merged image (Figure 4F) of phase and fluorescence settings (Figures 4D,E) for cells treated with HNT-RITC gives a clear picture of the localized nanotubes with red dye in the cell cytoplasm with distinct nuclear exclusion, which displays greater binding and aggregation of the tubes on the cell surface in $24 \mathrm{~h}$ compared to the $30 \mathrm{~min}$ treatment. After cell fixation (4 days), we see that cells treated with dye only was washed away with only minimal fluorescence remaining on the cells. While the HNT-RITC treated cells still showed significant fluorescence indicating a prolonged delivery of the dye from the clay nanotubes. Figures $\mathbf{4 G , H}$ show that the cells treated with halloysite nanotubes alone (negative controls) do not show any fluorescence by themselves.

The fluorescence images (middle) highlights nanotubes or dye localization in the outer region of the cell networks, while 


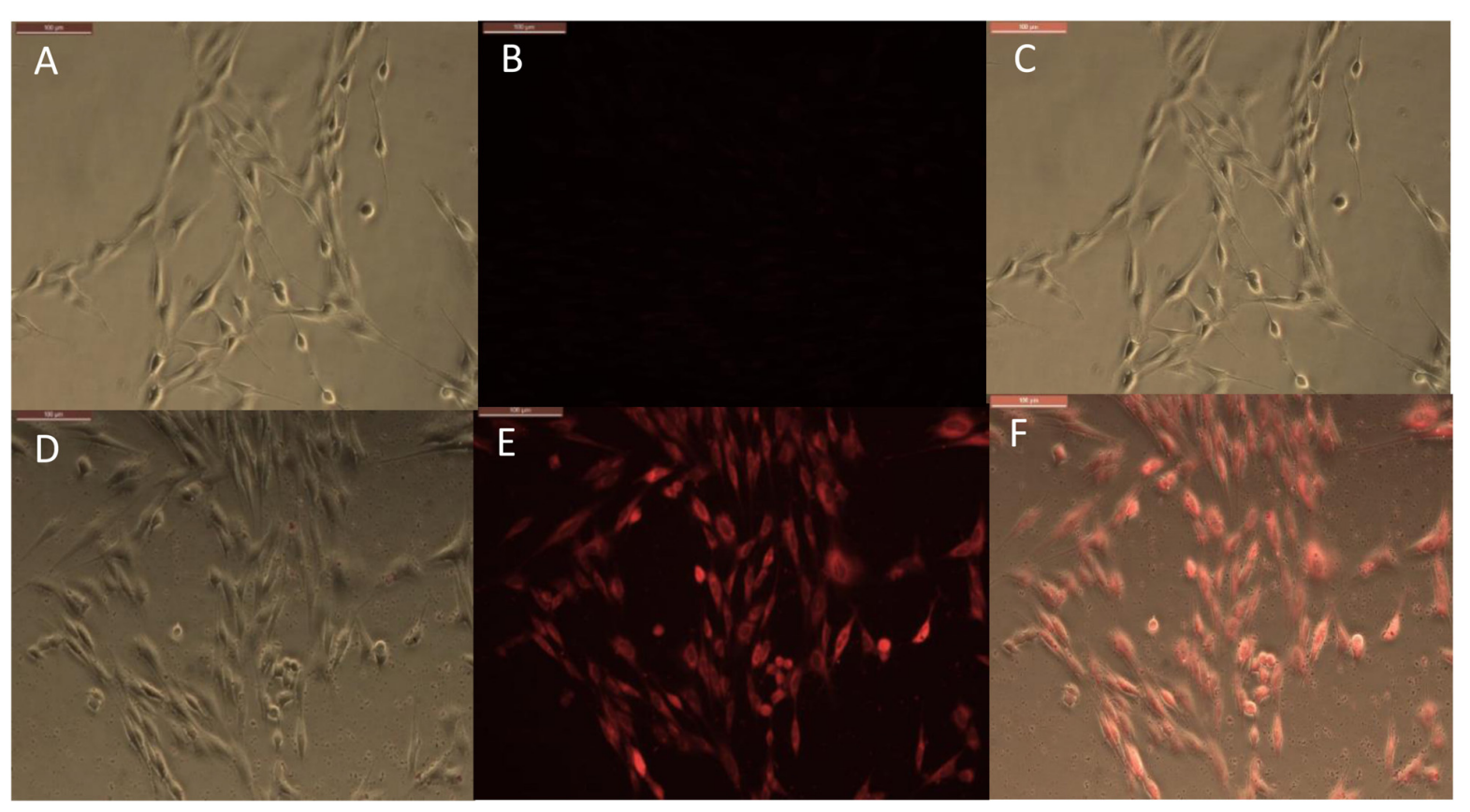

FIGURE 3 | Phase and fluorescence imaging of primary brain endothelial cells treated with RITC only (A,B), and with halloysite clay nanotubes loaded with RITC (D,E) after 30 min exposure. Merged images for the phase and fluorescence settings (C,F). Magnification $200 \mathrm{X}$, scale bar = 200 $\mu \mathrm{m}$.

the merged images (left) illustrate a clear picture of materials (nanotubes and dye) localization inside or on the cell surface.

\section{Halloysite Loading With Glutamic Acid and Ionomycin}

Glutamic acid has a negative charge and being loaded into the tube's lumens demonstrated weight percent change of $3.4 \pm 0.2 \mathrm{wt} 1 \%$, corresponding to the halloysite loading. Loading of ionomycin was $16.2 \pm 0.2 \mathrm{wt} \%$ (Figure 5). The percentages of glutamic acid and ionomycin encapsulation were estimated based on the weight change at different temperatures using thermogravimetric analysis. There is a consistency in the drugs loading results, probably, based on the similar loading mechanism enhanced by an attraction of negative drug molecules into the positive lumen of nanotubes. The used pristine halloysite had a zeta-potential value of $-30 \pm 2 \mathrm{mV}$ and after the drugs loading, it became $-45 \pm 1$ and $-48 \pm 2 \mathrm{mV}$ correspondingly for ionomycin and glutamic acid. These formulations provided an enhanced colloidal stability that took $3-4 \mathrm{~h}$ for settling for pure halloysite and $8-10 \mathrm{~h}$ in the loaded samples. The precipitation time for aqueous unloaded and loaded halloysite ranged from minutes to days, in correspondence to the respective zetapotential that were measured. Therefore, the ability to load these neurotransmitters into clay nanotubes is achievable but further testing on the surface area and inner lumen with the transmitters need to be performed to know their exact location along with in vitro testing.

These results demonstrate that one can sufficiently load selected brain drugs into halloysite nanotubes and deliver them into the cells in a manner similar to the procedure of loading
RITC. Furthermore, we will concentrate on the analysis of ionomycin delivery because we have a well-elaborated method to characterize the drug release kinetics with $\mathrm{Ca}^{2+}$ analysis.

\section{Delivery of Ionomycin - Halloysite Formulations Into Endothelial Cells $\left(\mathrm{Ca}^{2+}\right.$-Analysis)}

In real time calcium imaging, we observed that the cells response to ionomycin had a spiked increase in $\mathrm{Ca}^{2+}$ which decayed quickly due to clearance by cells as shown in baseline (Figure 6A). When we used halloysite alone, there was only a small response (Figure 6B). When ionomycin was encapsulated with halloysite, we achieved a higher response of $\mathrm{Ca}^{2+}$ for the same concentration $(1 \mu \mathrm{M})$ loaded that was also used for the control resulting in a gradual rise in $\mathrm{Ca}^{2+}$ which remained higher for a longer time period until it was diluted by the addition of any other stimuli. This increase of $\mathrm{Ca}^{2+}$ indicates the gradual and prolonged transport of ionomycin through halloysite across the cell membrane (Figures 6B,C). Each experiment was ended with ionomycin stimulation to ensure that the stimulus did not kill the cell under observation. To ensure that the cells were healthy and responding normally to other physiological stimuli, cells were tested with ATP, a well-known stimulator for BMVECs. Ionomycin is a well-known antibiotic and has been also known to induce cancer cell death and proliferation. Results showing sustained delivery of ionomycin might suggest a potential application of these formulations for cancer treatment (Park et al., 2005; MacLean and Yuste, 2009; Han et al., 2013).

All cells were stimulated with ionomycin at the end of experiment (B-E), except (A) which was stimulated by 


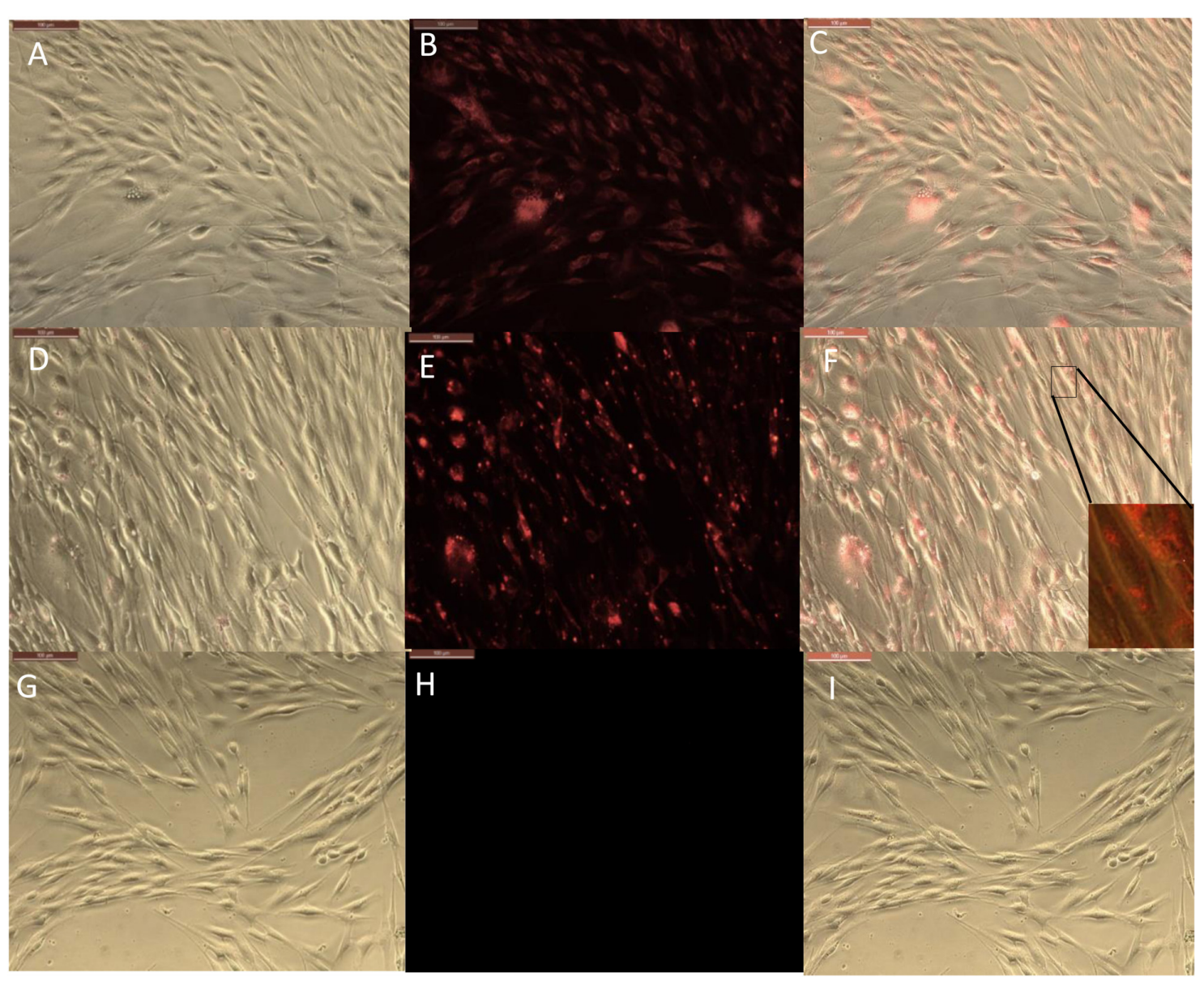

FIGURE 4 | Phase and fluorescence microscopic imaging of primary endothelial cells that were treated with RITC only (A,B), treatment with HNT-RITC formulations (D,E), and treatment with HNT only $(\mathbf{G}, \mathbf{H})$ in both phase (right) and fluorescent (middle) settings for $24 \mathrm{~h}$ exposure. Merged images for the phase and fluorescence settings $(\mathbf{C}, \mathbf{F}, \mathbf{l})$. Magnification $=200 \mathrm{X}$, scale bar $=100 \mu \mathrm{M}$.

HNT-ionomycin of $50 \mu \mathrm{g} / \mathrm{mL}$. This demonstrated that the cells were still responsive to $\mathrm{Ca}^{2+}$ changes, ensuring no cell death, and avoiding occurrence of false signals during the experiments.

$\mathrm{Ca}^{2+}$ peak analysis presented in Figure 7 allows us to come to following conclusions: stimulation by ionomycin (positive control) shows an instant peak of $\mathrm{Ca}^{2+}$ that decays quickly compared to HNT-ionomycin nanocapsules (50 and $10 \mu \mathrm{g} / \mathrm{mL}$ ) which shows a gradual influx of $\mathrm{Ca}^{2+}$ and higher delivery of ionomycin in the cells for both concentration (Figures 7A,B). Cells that responded to ATP showed a significant peak that is normally observed for physiological conditions (Figure 7C). Stimulus by halloysite alone produces a slight $\mathrm{Ca}^{2+}$ response, which was much less compared to HNT-ionomycin formulations with the cells showing no visible toxicity as well as remaining active afterward.

\section{Statistical Analysis of Calcium Response to Different Stimuli}

The graphs in Figure 7 show signals obtained for only 5 cells for each condition for simplification and clear representation of the data. The number of cells captured per frame for a condition being tested in an experiment act as a region of interest, and it ranged from 41 to 140 cells. After obtaining the calcium signals for different stimulations, the $\mathrm{Ca}^{2+}$ fluorescence intensity data as a function of time are used to extract the percentage of peak $\mathrm{Ca}^{2+}$ response above the baseline (Figure 8B) and the cells that responded to the stimuli (Figure $\mathbf{8 C}$ ). The time taken for the stimuli to reach the peak response (Figure 8D) was also extracted. The bar graphs are obtained by averaging the values over the region of interest from each condition used for the experiment. At least five conditions were tested here, three times. Overall, the number of cells analyzed was 1,232 for all wells and conditions reported for calcium imaging.

One can see that the calcium peak response above baseline gave us an idea of how high the calcium response to a stimulus is. The results (Figure $\mathbf{8 B}$ ) shows that the increase in peak calcium response above the baseline was $120 \%$ for HNT-ionomycin $(50 \mu \mathrm{g} / \mathrm{mL})$, and it was greater than for ionomycin alone (positive control) at $82 \pm 2 \%$.

The halloysite (negative controls) showed a slight $\mathrm{Ca}^{2+}$ response, which was insignificant at $16 \%$ compared to the high 


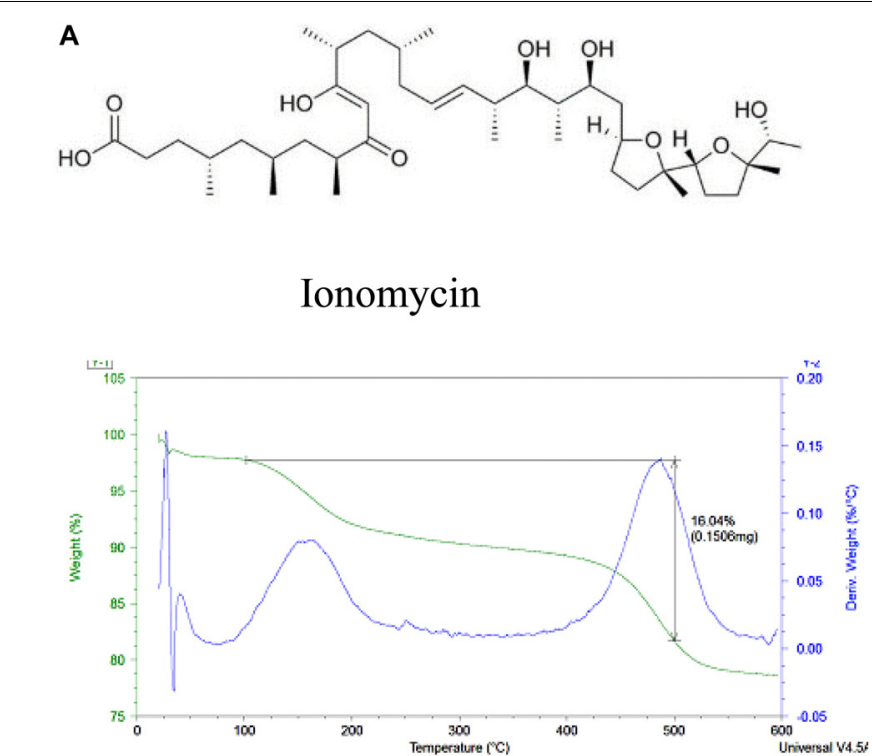

B<smiles>N[C](CCC(=O)O)C(=O)O</smiles>

Glutamic acid

FIGURE 5 | Thermogravimetric data for halloysite loaded with ionomycin and glutamic acid $\mathbf{( A , B ) . ~}$
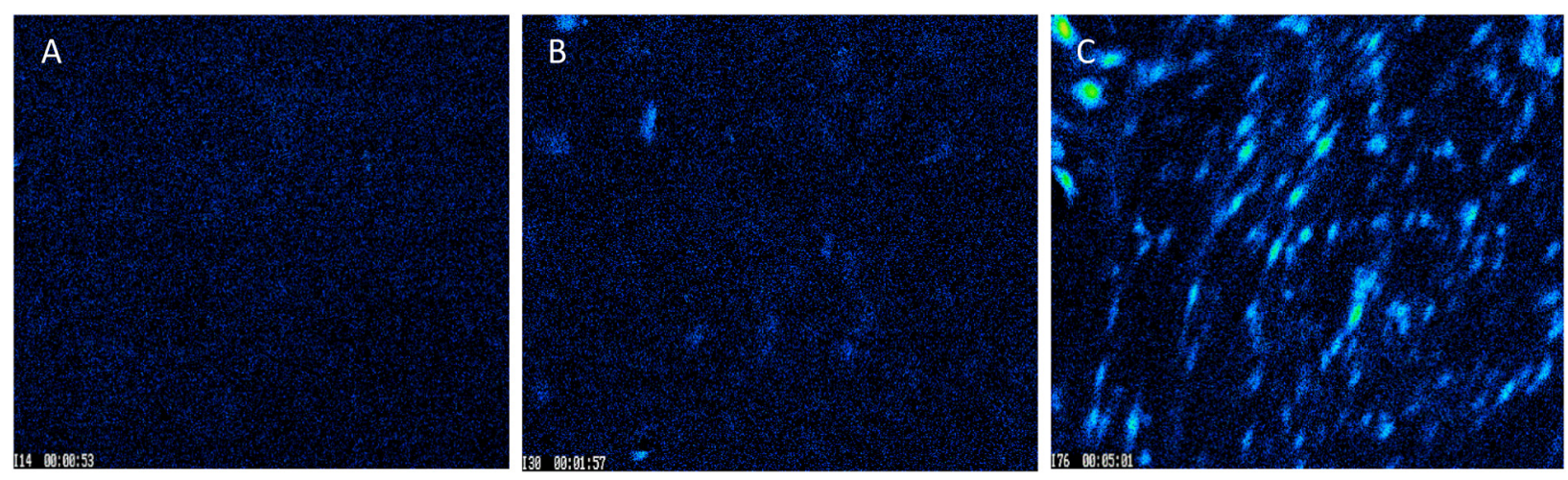

FIGURE 6 | Images captured for BMVECs during $\mathrm{Ca}^{2+}$ treatment: (A) before stimulation; (B) peak stimulation by $50 \mu \mathrm{g} / \mathrm{mL}$ of empty halloysite nanotube, and (C) peak stimulation by $50 \mu \mathrm{g} / \mathrm{mL}$ nanotubes loaded with ionomycin. Magnification = 200X.

response of $94 \%$ for the same concentration of the HNTionomycin samples. The results that the nanotubes alone can also produce much smaller $16 \%$ peak $\mathrm{Ca}^{2+}$ response suggest us that there is some form of advantageous cellular interaction and communication between the nanoclay and endothelial cell networks which is served by the signaling molecule, calcium. For ATP stimulation the signal was $40 \%$. The peak response to ATP showed that the cells were healthy and at normal physiological condition.

Each experiment had different numbers of cells giving rise to different regions of interest. Figure $\mathbf{8 C}$ represents the percentage of cells that responded for the given stimulus in an experiment. One can see that a higher number of cells responded to the HNT ionomycin formulation with $97 \%$ for concentration of $10 \mu \mathrm{g} / \mathrm{mL}$ and at $92 \%$ for $50 \mu \mathrm{g} / \mathrm{mL}$, while it was $65 \%$ for $50 \mu \mathrm{g} / \mathrm{mL}$ halloysite alone, $72 \%$ for $1 \mu \mathrm{M}$ ionomycin, and $76 \%$ for $100 \mu \mathrm{M}$ ATP. This result indicates that all the parameters discussed here are supported by a high response of cells, but the data specifically displays a higher value in the loaded samples compared to the other conditions tested.

Figure 8D represents the time taken for the cells to produce the peak calcium response. It tells us how delayed or instant the peak response was, indicating the delivery properties of halloysite clay nanotubes. The duration of release until peak calcium response after the stimulation was found to be $80 \mathrm{~s}$ for the nanoclay loaded with ionomycin at $10 \mu \mathrm{g} / \mathrm{mL}, 54 \mathrm{~s}$ for halloysite loaded with ionomycin at $50 \mu \mathrm{g} / \mathrm{mL}$ and $66 \mathrm{~s}$ for $50 \mu \mathrm{g} / \mathrm{mL}$ halloysite alone. This result along with results of Figures 8B,C explains that using a low concentration $10 \mu \mathrm{g} / \mathrm{mL}$ HNT-ionomycin formulation is enough to get enhanced delivery of ionomycin for a prolonged time as compared to using just ionomycin itself. Using a higher concentration $(50 \mu \mathrm{g} / \mathrm{mL})$ can increase this response further but delay is better achieved with the use of lower concentrations. 


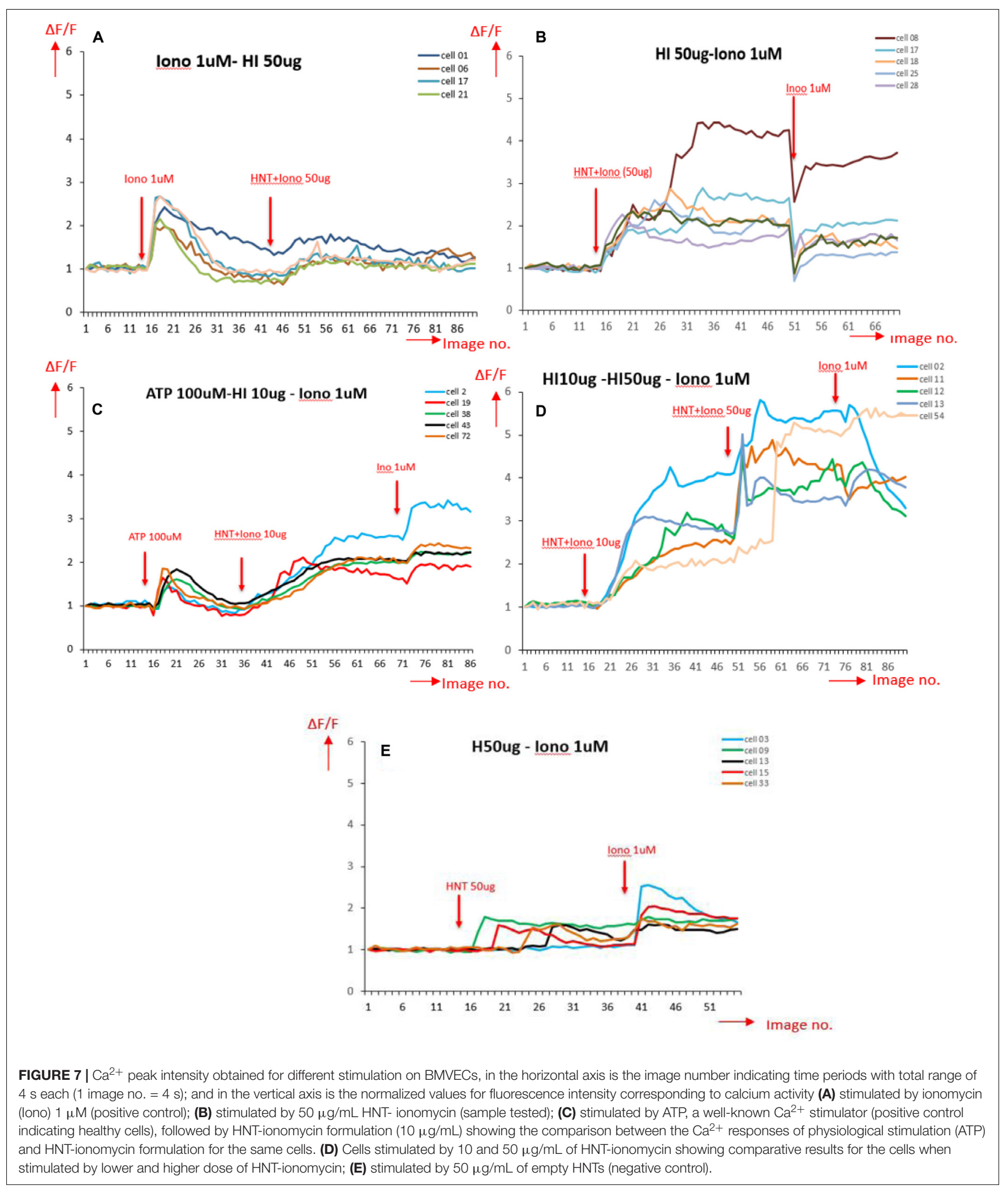

In contrast, the duration was very short for ionomycin $1 \mu \mathrm{M}$ at $13 \mathrm{~s}$ and ATP at $16 \mathrm{~s}$. The duration was found higher for the halloysite loaded and unloaded samples as compared to ionomycin and ATP in their soluble forms. This indicates that there is delayed diffusion from the nanotubes due to the soluble ionomycin and ATP release being much faster. 


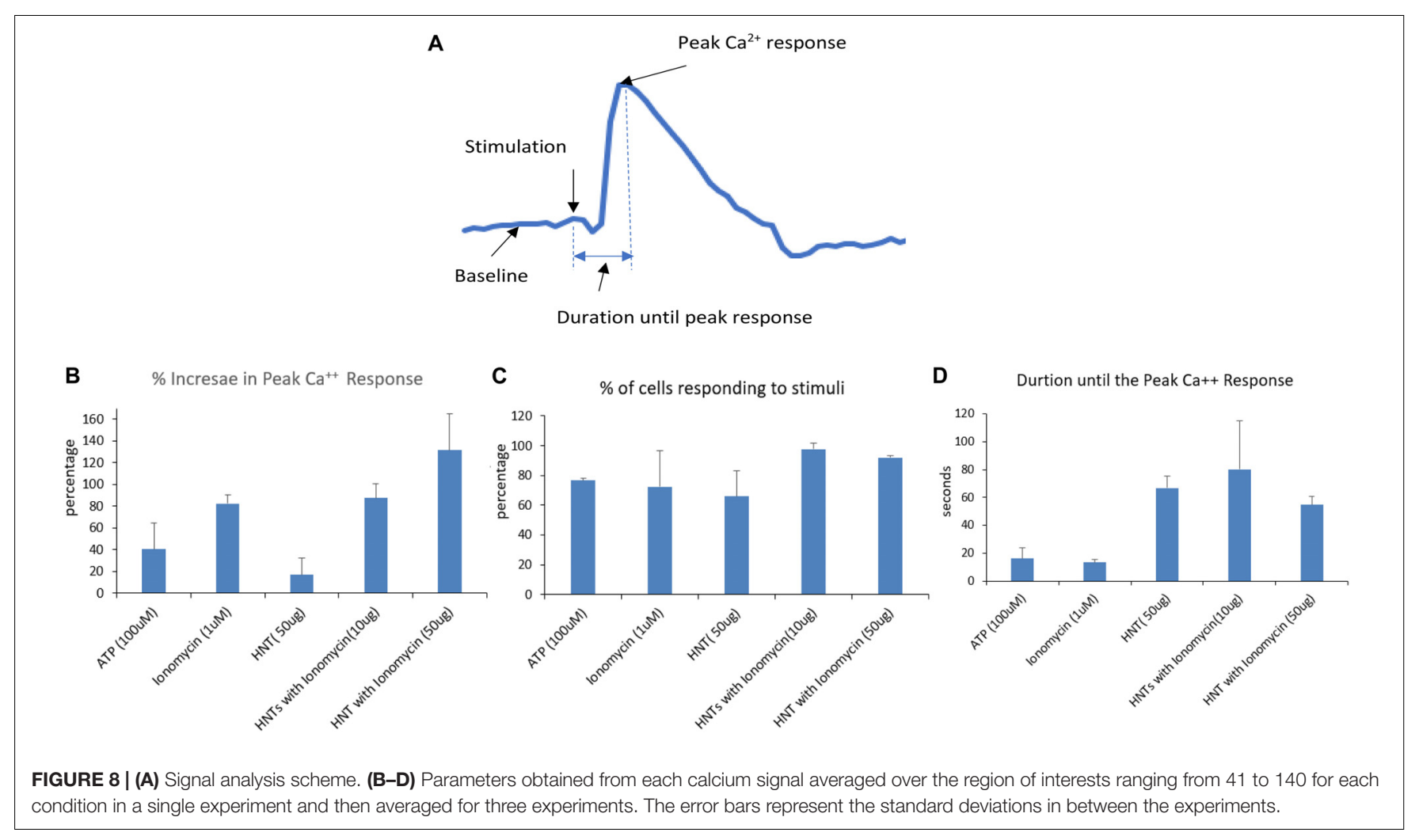

All the results discussed in Figures $7, \mathbf{8}$ indicate that the halloysite loaded with ionomycin showed delayed and gradual release of ionomycin into the cells, that once it reaches the peak response it continues to diffuse for a prolonged time which is expected to be up to $24 \mathrm{~h}$ as was observed for the nanotubes loaded with RITC Figures 3, 4. 24 h treatment of BMVECs with ionomycin concentration of $1 \mu \mathrm{M}$ used throughout the experiment didn't show any cytotoxicity to the cells.

\section{CONCLUSION}

Halloysite nanotubes have a great potential in delivering drugs effectively to the brain because they were not toxic to the endothelial cells, they were capable of slowly releasing drugs over various time spans ranging from minutes to hours, and are attracted to the cells that reside in the blood-brain barrier. The ability of halloysite to enhance the calcium response in BMVECs by loading it with ionomycin drastically extended the delivery time of the compound compared to the use of the ionophore alone (non-encapsulated). With this new information, we can extend this approach for treating brain cancer cells through drug delivery based upon the data of inhibitory effects of ionomycin on the cells and its use as a chemosensitizer. We confirmed a delayed and prolonged diffusion of the drug delivery mechanism due to the halloysite nanotubes loading cell probes (ionomycin + RITC). This provides a sustained delivery strategy for drug penetration across the blood-brain barrier.

\section{DATA AVAILABILITY STATEMENT}

All datasets generated for this study are included in the article/supplementary material.

\section{ETHICS STATEMENT}

The animal study was reviewed and approved for all cell studies carried out in this work, which used primary tissues derived from laboratory animals as approved by Louisiana Tech University IACUC (Louisiana Tech University IACUC, Center for Biomedical Engineering and Rehabilitation Science, Ruston, LA, United States).

\section{AUTHOR CONTRIBUTIONS}

MS: nanoformulation experiments under YL supervision. NP: cell culture treatments under MD: supervision. YL and $\mathrm{MD}$ writing the manuscript.

\section{FUNDING}

We thank Louisiana Board of Regents grant LaSpace-GSRA\#19287 for support of this work. Support by NSF - 1632891 grant was acknowledged. Any opinions, findings, and conclusions, or recommendations expressed in this report are those of authors and do not necessarily reflect the view of National Science Foundation. 


\section{REFERENCES}

Bennewitz, M., and Saltzman, W. (2009). Nanotechnology for delivery of drugs to the brain for epilepsy. Neurotherapeutics 6, 323-336. doi: 10.1016/j.nurt.2009. 01.018

Dzamukova, M., Naumenko, E., Badrutdinov, A., Lvov, Y., and Fakhrullin, R. (2015a). Enzyme-activated intracellular drug delivery with tubule clay nanoformulation. Sci. Rep. 5:10560. doi: 10.1038/srep 10560

Dzamukova, M., Naumenko, E., Rozhina, E., Trifonov, A., and Fakhrullin, R. (2015b). Cell surface engineering with polyelectrolyte-stabilized magnetic nanoparticles: a facile approach for fabrication of artificial multicellular tissuemimicking clusters. Nano Res. 8, 2515-2532.

Fakhrullina, G., Khakimova, E., Akhatova, F., Lazzara, G., Parisi, F., and Fakhrullin, R. (2019). Selective antimicrobial effects of curcumin @ halloysite nanoformulation: a Caenorhabditis elegans study. ACS Appl. Mater. Interf. 11, 23050-23064. doi: 10.1021/acsami.9b07499

Han, S., Tie, X., Meng, L., Wang, Y., and Wu, A. (2013). PMA and ionomycin induce glioblastoma cell death: activation-induced cell-death-like phenomena occur in glioma cells. PLoS One 8:e76717. doi: 10.1371/journal.pone.007 6717

Hu, Y., Chen, J., Li, X., Sun, Y., Huang, S., Li, Y., et al. (2017) Multifunctional halloysite nanotubes for targeted delivery and controlled release of doxorubicin in-vitro and in-vivo studies viability tests and microscopy study. Nanotechnology 28:375101. doi: 10.1088/1361-6528/aa 8393

Kamalieva, R., Ishmukhametov, I., Batasheva, S., Rozhina, E., and Fakhrullin, R. (2018). Uptake of halloysite clay nanotubes by human cells: colourimetric. Nano Struct. Nano Objects 15, 54-60.

Kaushik, V., Yakisich, J., Kumar, A., Azad, N., and Iyer, A. (2018). Ionophores: potential use as anticancer drugs and chemosensitizers. Cancers 10:360. doi: $10.3390 /$ cancers 10100360

Kruchkova, M., Danilushkina, A., Lvov, Y., and Fakhrullin, R. (2016). In vivo toxicity study of nanoclays and graphene oxide with Paramecium caudatum. Environ. Sci. Nano 3, 442-452.

Liu, M., Fakhrullin, R., Novikov, A., Vinokurov, V., Panchal, A., Fu, Y., et al. (2019). Tubule nanoclay-organic heterostructures for biomedical applications. Macromol. Biosci. 19:1800419. doi: 10.1002/mabi.201800419

Liu, M., Jia, Z., Jia, D., and Zhou, C. (2014). Recent advances in halloysite research. Prog. Polym. Sci. 39, 1498-1514.

Long, Z., Wu, Y.-P., Gau, H.-Y., Li, Y.-F., He, R.-R., and Liu, M. (2018). Functionalization of halloysite nanotubes via grafting of dendrimer for efficien intracellular delivery of siRNA. Bioconjugate Chem. 29, 2606. doi: 10.1021/acs. bioconjchem. 8 b00321

Lvov, Y., Wang, W., Zhang, L., and Fakhrullin, R. (2016). Halloysite clay nanotubes for loading and sustained release of functional compounds. Adv. Mater. 28, 1227-1250. doi: 10.1002/adma.201502341

MacLean, J., and Yuste, R. (2009). Imaging action potentials with calcium indicators. Cold Spring Harb. Protoc. 2009:pdb.prot5316. doi: 10.1101/pdb. prot5650

Mahringer, A., Ott, M., and Fricker, G. (2013). "The blood-brain barrier: an introduction to its structure and function," in The Blood Brain Barrier, Vol. 10, eds G. Fricker, M. Ott, and A. Mahringer (Berlin: Springer), 1-20. doi: $10.1177 / 0333102418786261$

Mbagwu, S., and Filgueira, L. (2020). Differential expression of CD31 and von willebrand factor on endothelial cells in different regions of the human brain: potential implications for cerebral malaria pathogenesis. Brain Sci. 10:31. doi: 10.3390/brainsci10010031

Mehdia, Y., Fizira, M., Itatahinea, A., Hea, H., and Dramoua, P. (2018). Preparation of multifunctional PEG-graft-halloysite nanotubes for controlled drug release, Tumor cell targeting, and bio-imaging. Coll. Surfaces B Biointerf. 170, 322-329. doi: $10.1016 /$ j.colsurfb.2018.06.042
Morgan, A. J., and Jacob, R. (1994). Ionomycin enhances Ca2+ influx by stimulating store-regulated cation entry and not by a direct action at the plasma membrane. Biochem. J. 300, 665-672. doi: 10.1042/bj3000665

Park, C., Hahm, E., Lee, J., Jung, K., Rhee, H., Yang, C., et al. (2005). Ionomycin downregulates $\beta$-catenin/Tcf signaling in colon cancer cell line. Carcinogenesis 26, 1929-1933. doi: 10.1093/carcin/bgi145

Pehlivan, S. (2013). Nanotechnology-based drug delivery systems for targeting, imaging and diagnosis of neurodegenerative diseases. Pharm. Res. 30:2499. doi: 10.1007/s11095-013-1156-7

Santos, A., Pereira, I., Veiga, F., Reis, S., Saleh, M., and Lvov, Y. (2019). Biomedical potential of clay nanotube formulations and their toxicity assessment. Expert Opin. Drug Deliv. 16, 1169-1182. doi: 10.1080/17425247.2019.1665020

Silva, G. (2008). Nanotechnology approaches to crossing the blood-brain barrier and drug delivery to the CNS. BMC Neurosci. 9:S4. doi: 10.1186/1471-2202-9S3-S4

Thiel, V., and Audus, K. (2001). Nitric oxide and blood-brain barrier integrity. Antioxid. Redox Signal. 3, 273-278.

Vergaro, V., Abdullayev, E., Cingolani, R., Lvov, Y., and Leporatti, S. (2010). Cytocompatibility and uptake for clay nanotubes. Biomacromolecules 11, 820-229.

Wang, G., Qian, P., Xu, Z., Zhang, J., Wang, Y., Cheng, S., et al. (2012). Regulatory effects of the JAK3/STAT1 pathway on the release of secreted phospholipase A2-IIA in microvascular endothelial cells of the injured brain. J. Neuroinflammation 9:170. doi: 10.1186/1742-2094-9-170

Wang, X., Gong, J., Gui, Z., Hu, T., and Xu, X. (2018). Halloysite nanotubesinduced $\mathrm{Al}$ accumulation and oxidative damage in liver of mice after 30-day repeated oral administration. Environ. Toxicol. 33, 623-631. doi: 10.1002/tox. 22543

World Health Organization [WHO] (2020). Epilepsy. Geneva: World Health Organization. Available online at: https://www.who.int/news-room/factsheets/detail/epilepsy

Wu, Y.-P., Yang, J., Gao, H.-Y., Shen, Y., Jiang, L., Zhou, C., et al. (2018). Folateconjugated halloysite nanotubes, an efficient drug carrier, deliver doxorubicin for targeted therapy of breast cancer. ACS Appl. Nano Mater. 1, 595-608.

Yamamoto, K., Furuya, K., Nakamura, M., Kobatake, E., Sokabe, M., and Ando, J. (2011). Visualization of flow-induced ATP release and triggering of $\mathrm{Ca} 2+$ waves at caveolae in vascular endothelial cells. J. Cell Sci. 124, 3477-3483. doi: $10.1242 /$ jcs.087221

Yang, J., Wu, Y., Shen, Y., Zhou, C., Li, Y.-F., He, R.-R., et al. (2016). Enhanced therapeutic efficacy of doxorubicin for breast cancer using chitosan oligosaccharide-modified halloysite nanotubes. ACS Appl. Mater. Interfaces 8, 26578-26590. doi: 10.1021/acsami.6b09074

Zhang, Z., Luo, X., Wu, Y.-P., Wu, F., Li, Y.-F., He, R.-R., et al. (2019). Rod in tube: a novel nanoplatform for highly effective chemo-photothermal combination therapy toward breast cancer. ACS Appl. Mater. Interfaces 11, 3690-3703. doi: 10.1021/acsami.8b17533

Zhao, X., Wan, Q., Fu, X., Meng, X., Ou, X., Zhong, R., et al. (2019). Toxicity evaluation of one-dimensional nanoparticles using caenorhabditis elegans: a comparative study of halloysite nanotubes and chitin nanocrystals. ACS Sustain. Chem. Eng. 7, 18965-18975.

Conflict of Interest: The authors declare that the research was conducted in the absence of any commercial or financial relationships that could be construed as a potential conflict of interest.

Copyright (c) 2020 Saleh, Prajapati, DeCoster and Lvov. This is an open-access article distributed under the terms of the Creative Commons Attribution License (CC BY). The use, distribution or reproduction in other forums is permitted, provided the original author(s) and the copyright owner(s) are credited and that the original publication in this journal is cited, in accordance with accepted academic practice. No use, distribution or reproduction is permitted which does not comply with these terms. 